\title{
Tránsito, comercio y actividad económica en la Sisapo Altoimperial *
}

\author{
Mar Zarzalejos Prieto, Alicia Arévalo González ** \\ Y CARMEN FERNÁNDEZ OCHOA ***
}

\begin{abstract}
RESUMEN ABSTRACT
Presentamos en este trabajo un ensayo de aproximación a la dinámica económica reflejada por la ciudad de Sisapo durante la etapa altoimperial. Los argumentos que sinen de apoyo a este

análisis derivan de la información numismática y cerámica asociada a los cortes estratigráficos realizados en el yacimiento de La Bienvenida (Almodóvar del Campo, Ciudad Real). La suma de ambos registros informativos permite, asimismo, mostrar la vitalidad de las diversas vías de comunicación que canalizaron el tráfico comercial en el núcleo a lo largo de los siglos I y $\mid$ d.C.

PALABRAS CLAVE: Economía, Comercio, Minería, Vías de comunicación, Numismática, Cerámica.

At this article we present a preliminary study about economic development at Sisapo City during the Roman period. The arguments that subject at analysis are founded on coins and potteries coming from the archaeological excavation at the site of La Bienvenida (Almodóvar del Campo, Ciudad Real, Spain). This information permits to show the vitality of roman roads that canalise the trade during the first and second century A.C.

KEY WORDS:

Economy, Trade, Antiquity Mining, Roman Roads, Coinage, Roman Pottery.
\end{abstract}

* Este artículo fue presentado como comunicación al II Congreso de Arqueología Peninsular cebrado en Zamora en 1996. El gran retraso en la edición de las Actas que reúnen los trabajos de las épocas romana y medieval y el riesgo consiguiente de desfase cronológico del trabajo, nos ha impulsado ha presentarlo en Espacio, Tiempo y Forma en su versión original íntegra. Agradecemos a D. a Pilar Fernández Uriel las enormes facilidades que nos ha proporcionado para que el trabajo viera la luz.

** El presente trabajo forma parte del proyecto de investigación financiado por la Fundación Caja Madrid.

*** Consejería de Cultura de la Comunidad de Castilla-La Mancha, Universidad Autónoma de Madrid. 


\section{INTRODUCCIÓN}

Los trabajos efectuados en los últimos años en el yacimiento de La Bienvenida (Almodóvar del Campo, Ciudad Real) han potenciado, de manera importante, el conocimiento de la dinámica histórica de la ciudad de Sisapo (Zarzalejos, 1994 y 1995; Zarzalejos et alii, 1994; Fernández Ochoa et alii, 1994; Zarzalejos, e.p.). Este avance, con reflejo en el incremento de datos sobre la cultura material, hace factible la realización de un ensayo preliminar sobre el comportamiento económico de la ciudad en las diferentes etapas de su actividad. Esta comunicación supone la continuidad de una de las líneas de investigación sobre el yacimiento, que pretende mostrar la fecunda relación entre Arqueología y Numismática cuando ambas disciplinas suman sus progresos para la caracterización global de un núcleo antiguo (Arévalo y Zarzalejos, 1996, 161 ss.).

Abordaremos en este trabajo, el análisis de la etapa altoimperial, utilizando como indicadores dos segmentos bien elocuentes de la cultura material adscrita a este período: las producciones cerámicas y el numerario. Entre las primeras, vamos a manejar aquéllas cuya procedencia puede precisarse a través de la identificación inmediata de la producción o mediante la realización de análisis físico-químicos. Tal sería el caso de las diferentes series de terra sigillata (itálica, gálica e hispánica), las cerámicas de paredes finas y algunas producciones anfóricas y lucernarias. No creemos necesario insistir en el valor que estos materiales poseen como fósil director. Sí destacaremos, en cambio, que las conclusiones parciales de estudios monográficos sobre material descontextualizado que hemos ido dando a conocer (Fernández Ochoa y Seldas, 1987; Fernández Ochoa y Zarzalejos, 1991; Fernández Ochoa y Zarzalejos, 1993), se sumarán ahora a los datos obtenidos en diversos cortes estratigráficos. Lógicamente, el análisis del comportamiento de estos materiales en el tiempo proporcionará una visión mejor contrastada de la dinámica comercial y el marco de relaciones en que se desenvolvió Sisapo durante el primer siglo de la Era.

Por su parte, la moneda es un objeto arqueológico más a la hora de ayudar a verificar las transformaciones que una ciudad sufre a lo largo de un período dado. La información que nos proporciona a través de su dispersión y procedencia es semejante a la de cualquier otro elemento de la cultura material. El hecho de que la casi totalidad de los hallazgos monetales que conocemos de La Bienvenida (Arévalo, 1995) sean piezas de bronce, permitirá determinar el movimiento de población que hubo en diferentes etapas. Por el contrario, las piezas de plata son, además, testimonio de intercambios comerciales, a la vez que pueden viajar solas de mano en mano debido a su valor. El escaso numerario de plata recupera- 
do, tan sólo un denario de Tiberio de la ceca de Lugdunum, no posibilita extraer conclusiones a este respecto.

Además de valoraciones intrínsecas a los propios materiales, la evidencia que proporcionan cerámicas y monedas ofrece inestimable información acerca del soporte físico que canaliza la afluencia de bienes al yacimiento: las vías de comunicación. En efecto, los datos derivados de la situación de Sisapo en la red caminera de época romana pueden ser leídos con claridad a través de la comparación de sus conjuntos materiales y numismáticos con los de los núcleos con los que se mantuvo unida en la Antigüedad. Todos estos elementos de juicio se unirán a la información contenida en las fuentes clásicas, permitiendo establecer conclusiones preliminares sobre la actividad económica del centro en diferentes momentos de la etapa altoimperial.

\section{LOS PRECEDENTES: LA ETAPA TARDORREPUBLICANA}

La problemática de la fase republicana del yacimiento ha sido abordada con carácter monográfico en otro lugar (Arévalo y Zarzalejos, 1996). No obstante, es preciso comentar, aunque sea brevemente, cuál es la información disponible sobre la etapa previa a la que será objeto de análisis más detallado, a fin de determinar las transformaciones que se operan en el núcleo a partir de época augústea.

Tras un largo proceso histórico que hunde sus raíces en las postrimerías del siglo VIII o inicios del VII a.C. (Fernández Ochoa et alii, 1994, 143151; Fernández Ochoa et alii, 1993), los momentos primeros de la etapa romana de la ciudad de Sisapo son aún poco conocidos por vía arqueológica. Sólo se han excavado estratos adscribibles a este período en los cortes A-1 (a b) y E-2, si bien se han recuperado algunos materiales en superficie o en capas revueltas (Zarzalejos, 1995, 373-375 y 384-386). Su definición material está constituida por cerámica "campaniense» B y Boïde (formas Lamboglia 1, 4, 5 y 7), cerámica de paredes finas (formas Mayet II y III), algún ejemplar de ánfora Dressel $1 \mathrm{~B}$ o $\mathrm{C}$ y lucernas de tipo Dressel 3. La cronología asociada a este conjunto material posibilita su inserción en un contexto situable a partir de fines del siglo $\|$ o inicios del । a.C. La presencia de estos productos en La Bienvenida revela la inmersión del centro en los canales de distribución de productos itálicos. El registro de elementos afines en yacimientos significativos del entorno sisaponense, como Mirobriga (Pastor et alii, 1992, 74) o Mina Diógenes (Domergue, 1967, 33-34) pone de relieve el funcionamiento republicano del segmento entre Metellinum y Sisapo de la vía 29 del Itinerario de 
Antonino (Zarzalejos, 1995, 181 ss.). Este hecho remarca la continuidad de una ruta de comunicación que se muestra activa desde el momento de fundación de La Bienvenida y que conecta esta área del reborde suroccidental de la Meseta con la Baja Andalucía a través de la que, en tiempos romanos, será conocida como vía de la Plata (Zarzalejos, 1995, 115-138; Fernández Ochoa et alii, 1994, 21-22; Zarzalejos et alii, 1995, 186).

Aunque se nos escapa aún el impacto real de la primera presencia romana en el lugar, parece fuera de duda que el modelo de actuación romano consistió en el aprovechamiento de un núcleo preexistente, dado el carácter estratégico que el centro poseyó desde su fundación para el control de dos productos mineros: el cinabrio y la galena argentífera (Zarzalejos, 1995, 903-4). Este hecho viene confirmado por el tipo de numerario circulante en el yacimiento - monedas de kastilo, Obulco, Corduba, belikio y sekaisa-, habitual en los lugares relacionados con la explotación minera. Por su parte, las fuentes informan del funcionamiento de la explotación minera sisaponense bajo el control de una societas publicanorum. Así se encuentra explícito en una indicación ciceroniana contenida en la Segunda Filípica (Phil 2, 19, 48), que evidencia su funcionamiento durante la primera mitad del siglo । a.C. Otros documentos de excepción son la inscripción tardorrepublicana hallada en Córdoba, donde se menciona que la funcionalidad principal de la servitus viae impuesta por la societas sisaponensis sería el transporte del mineral (Ventura, 1993), así como la contramarca S.S encontrada en monedas de kese y Carmo, ambas del siglo । a.C. y en un cubo hallado en Posadas (Córdoba) (García-Bellido, 1986, 20).

Desde el punto de vista de la circulación monetaria se pueden distinguir dos focos de alimentación: uno cercano y fluido atestiguado por las monedas de kastilo (García-Bellido, series IV y Vla), Obulco (Arévalo, series III, IV y Va) y Corduba (Vives, CXVIII-1) ; ello es lógico puesto que todas ellas están próximas, acuñaron en abundancia y circularon habitualmente en áreas mineras (García Bellido, 1982, 95-137; Arévalo González, 1993, 489-513). El otro conjunto de monedas es de la Citerior - belikio (Vives, XLIV-3), sekaisa (Vives, LXV-11) - lo que indica que parte de la población procedía de allí. Este trasvase de moneda de bronce del norte está bien comprobado en otras áreas de conocida actividad minera (Otero Morano, 1993, 49-58; Blázquez Cerrato, 1993, 242-245) y viene a demostrar que debió ser habitual el desplazamiento de personal especializado hacia zonas de economías similares (García-Bellido, 1986, 34-38). Las vías de penetración que sirvieron de soporte a este trasiego debieron ser algunos de los canales que hicieron posible la llegada a Sisapo de materiales de procedencia itálica. Es factible, por tanto, que los segmentos de la vía 29 
que conectan la ciudad con el valle del Ebro se muestren bastante activos en estos momentos. Así autoriza a pensarlo el hallazgo de producciones campanienses en yacimientos estrechamente conectados al camino (Mena, 1988, 29-34 y 38).

Por otra parte, si comparamos el porcentaje de numerario circulante en las ciudades de Cástulo y Sisapo se observa que durante la etapa republicana fue más alto en Cástulo (Chaves Tristán, 1987-88, 621-628), con un $57,1 \%$, que en Sisapo, con un $21 \%$ (Arévalo, 1995, 132); mientras que los datos se invierten en la etapa altoimperial, Cástulo con un $42,8 \%$ y Sisapo con un $57,1 \%$. Quizás la acreditada expansión del área de control de Cástulo, durante la República, en las explotaciones mineras del norte de Jaén y el Sureste de Ciudad Real, podría llevar a preguntarse si fue también Cástulo quien gestionó las minas de plata más inmediatas a Sisapo. Ello quizás explicaría el mayor porcentaje de numerario que encontramos en ella.

\section{LA ETAPA AUGÚSTEA}

Durante esta fase el núcleo sisaponense experimenta un fenómeno de potenciación importante cuyas repercusiones se dejan sentir en una interesante actuación urbanística, marcada por el signo de la monumentalización. La prosperidad que traduce el urbanismo se ve secundada en lo material por un rico conjunto cerámico y numismático.

\subsection{Indicadores materiales}

La vitalidad del comercio itálico que mostraban los niveles de época tardorrepublicana se incrementa ahora de modo más que notable. Los datos aportados por el conjunto de t.s.i. exhumado en los cortes $A-1$ (a b) y E-2, permiten aquilatar las fechas iniciales de la presencia de estos productos en el yacimiento. En efecto, la documentación de formas arcaicas implica que las primeras importaciones itálicas en el yacimiento cuentan con un punto de partida situable a partir de los años 40-30 a.C. Este dato matiza la información derivada del conjunto de superficie, cuyos ejemplares más antiguos podían situarse en torno al cambio de Era (Fernández Ochoa y Zarzalejos, $1991,270)$. Sugerente a efectos comparativos, resulta la constatación en la cercana Miróbriga de un interesante conjunto de piezas arcaicas y precoces. No obstante, el grueso de sus importaciones se sitúa a fines de la etapa republicana e inicios del periodo augústeo (Pastor et alii, 1992, 78-9). 
Por lo que respecta al centro, o centros, de origen de la T.S.I. de Sisapo, la información de las marcas de oficina en nuestros registros estratigráficos resulta expresiva. Poseemos evidencia de productos firmados por Ateius en el corte E-2 (Zarzalejos, 1995, fig.136, núm. 24 y 25). Su documentación en otros yacimientos hispanos permite situar a este ceramista a la cabeza de las importaciones de t.s.i., si bien permanece sin solucionar la cuestión de la procedencia de los productos ateianos hallados en el territorio peninsular. Respecto a la cronología, los productos de Ateius han sido hallados en Conímbriga en contextos datables entre fines del siglo I a.C. y las dos primeras décadas del siglo siguiente (Delgado et alii, 1975,40 ). En su mayor parte, parecen corresponder a los últimos momentos del período augústeo, o a inicios del de Tiberio. Esta es también la cronología propuesta para los ejemplares cordobeses y numantinos (García y Bellido, 1970, 11; Romero, 1985, 35).

También se ha testimoniado la presencia de un sello perteneciente a Archebus, uno de los trabajadores del taller de L. Vmbricivs radicado en Arezzo (Zarzalejos, 1995, fig.136, núm. 26). Su producción, a juzgar por el número de marcas conocido, no es demasiado difundida en nuestro suelo: Tarragona y Comillas (Oxe y Comfort, 1968, 549) y también Lérida (Pérez Almoguera, 1983-4, 130-2). No deja de ser significativo que las grafías y nexos de nuestro ejemplar resulten próximas a las de un sello originario de Mérida, fechado en los años inmediatos al cambio de Era (Pérez Outeriño, 1990, 91, núm. 118).

La llegada a Sisapo, en tiempos augústeos, de producciones puteolanas está acreditada por el hallazgo de marcas pertenecientes a $N$. Naevius (Zarzalejos, 1995, fig.147, núm. 7). Sellos de este ceramista se han identificado en Itálica, Tarragona (Beltrán, 1990, 71), Sagunto (Montesinos, 1991, 39), Herrera de Pisuerga (Pérez González, 1989, 154-5) y, quizá, Segóbriga (Sánchez-Lafuente, 1990, 77). De origen posiblemente puteolano puede ser también la marca HERME hallada en el corte A-1 (a b) (Fernández Ochoa et alii, 1994, fig.10, núm. 2). Quizá esta marca pueda identificarse con el sello de Hermeiscus (Oxe y Comfort, 1968, 219), alfarero de Puteoli documentado en Ampurias y Cartagena (Beltrán, 1990, 71). Otros yacimientos peninsulares han proporcionado marcas quizá relacionadas con este mismo ceramista; así ocurre en Ibiza (Fernández et alii, 1992, 55) o Segóbriga, donde aparece una cartela de similares características con texto HER atribuido a HERTORIVS (Sánchez-Lafuente, $1990,74)$. Con el mismo contenido se constatan tres marcas procedentes de Mérida, una de las cuales, incompleta, ofrece el nexo de $\mathrm{H}-\mathrm{E}$, como en el ejemplar de La Bienvenida (Pérez Outeriño, 1990, 61-2). La atribución segura de estos casos no resulta fácil, dado lo abreviado de su texto y 
las diversas posibilidades de relación con otros alfareros cuyo cognomen empieza por HER (Hermeiscus, Hermaiscus, Hermiscus o Heraclida). No obstante, la identificación de productos puteolanos en el yacimiento sisaponense y otros puntos del interior, vuelve a poner en solfa el problema de la difusión eminentemente costera de estos alfares en la Península Ibérica, asunto sobre el que se han pronunciado ya otros autores (Balil, 1976, 70; Pérez González, 1989, 155). Con posterioridad al último trabajo citado, la nómina de productos de Puteoli ha seguido enriqueciéndose con los aportes de Segóbriga (Sánchez-Lafuente, 1990, 64) y Mérida (Pérez Outeriño, $1990,133)$, entre otros. Significativa resulta la llegada de estas series a la capital lusitana, comunicada por vía directa con Sisapo.

Otra especie cerámica expresiva de la inmersión de la ciudad en las redes de distribución de productos itálicos es el conjunto de Paredes Finas asociable al período que ahora tratamos. Entre las formas registradas en estratos de cronología augústea se cuentan los cubiletes Mayet $V$ con particularidades afines a las de la variante V B (Zarzalejos, 1995, fig.151, núm. 39-41), o también la forma Mayet VIII con variantes decoradas (Fernández Ochoa et alii, 1994, fig.35, núm. 16-19; Zarzalejos, 1995, fig.149, núm. 19-21). La proliferación de estas últimas en la Bética induce a algunos autores a plantear su posible filiación meridional, circunstancia ésta que corrobora la inmersión de Sisapo en los canales de difusión de productos de procedencia bética (López Mullor, 1989, 122-3). Asimismo hemos constatado la forma Mayet XIV (Zarzalejos, 1995, fig.151, núm. 3638 ); si bien desconocemos el origen de estos productos, la cronología general del tipo parece que debe ubicarse en época augústea (Mayet, 1975, 52). También los perfiles de la forma Mayet XXI, Marabini XXXI, encuentran ilustración en La Bienvenida (Zarzalejos, 1995, fig.151, núm. 33-35). Estas piezas presentan pastas de coloración gris oscura, con acabado alisado y sin engobe. Con características similares están documentadas significativamente en Mirobriga (Pastor et alii, 1992, 100, fig.19, núm. 37).

Por último, podríamos hacer uso de otros indicadores tales como las cerámicas romanas de imitación con barniz rojo, término que proponemos como alternativo al de las cerámicas tipo Peñaflor (Fernández Ochoa et alii, 1994, 112-113). La reiterada localización de estos productos en diferentes puntos de la Bética hace posible radicar en ella sus centros de producción. Significativamente, estas cerámicas se localizan también en Miróbriga (Pastor et alii, 1992, 82) y Mina Diógenes (Domergue, 1967, 76-77).

La prosperidad y dinamismo que revelan la presencia de las especies comentadas encuentra reflejo en el variado numerario adscribible al momento. El conjunto está compuesto por dos monedas de Caesaraugusta 
(RPC 322 y 314), una de Cartagonova (RPC 170), una de Ercávica (RPC 459), dos de Colonia Patricia (RPC 129), una de Traducta (RPC 108) y una de Nemausus (RPC 523) (Arévalo, 1995, 133).

\subsection{La ciudad en época augústea: actividades económicas y comerciales}

El fenómeno de potenciación urbanística de que Sisapo fue objeto en época augústea se encardina en un plan de largo alcance con manifestaciones bien evidentes en todo el territorio hispano. En opinión de $\mathrm{M}$. Bendala (1990, 25 ss.), la obra desarrollada por Augusto responde a una planteamiento globalizador, fruto de una situación nueva que emana de la finalización de las guerras de conquista y de la posibilidad, por vez primera, de considerar la Península en un marco totalizador. Este hecho incide, según el citado autor, en la elección del emplazamiento de dos de las ciudades más emblemáticas de la obra augústea en Hispania: Emerita Augusta y Caesaraugusta. Con independencia de precedentes indígenas anteriores, posible en el caso de la primera y constatado por las fuentes en el de la segunda, el emplazamiento de ambas es muestra de una planificación cuidada desde el punto de vista macroterritorial (Bendala, 1990, 38 ). Su conversión en sendos nódulos de comunicación viaria ayuda a perfilar la aplicación de un modelo organizativo que necesariamente debió partir de un conocimiento previo del territorio, posiblemente derivado de la obra cartográfica de Agripa.

Estas observaciones nos parecen un excelente punto de partida a la hora de buscar encuadre explicativo para el fenómeno de potenciación urbana que experimenta Sisapo en época augústea. Por un lado, ha de prestarse atención al interés e intensidad que debió experimentar la explotación minera por aquellos tiempos. Las referencias de Estrabón al minio, según Chic (1991, 7 ss y 22-26), hacen suponer que la dedicación imperante dada al mercurio a partir de época augústea fue para la amalgama de metales nobles. A juicio del citado autor, las monteras de cobre oxidantes, abundantes en el área cordobesa contuvieron oro (N.H., XXXIV, 4), para cuyo tratamiento resultó altamente eficaz la técnica de amalgama con mercurio. El establecimiento de la vía Corduba-Sisapo, en vigor al menos desde época tardorrepublicana, permitiría que el minio de Sisapo llegara a los filones cupríferos de Sierra Morena (Melchor Gil, 1993, 6889); es muy posible que el desplazamiento de numerario se realizara en función de esta actividad económica, de ahí que encontremos en el propio yacimiento de La Bienvenida moneda de la Colonia Patricia. Este hecho contribuiría a aclarar la mayor proporción de numerario circulante obser- 
vable en Sisapo durante estos momentos. Así, esta ciudad presenta un porcentaje del $57,1 \%$ que contrasta con el descenso que muestra Cástulo $(42,8 \%)$ en relación con el período republicano.

La nueva funcionalidad dada al mercurio explicaría, según Chic (1991, 26-27), la confiscación de las minas de Sexto Mario en esta zona (Tac. Ann. $6,19,11)$ y el interés particular que el Estado muestra por el control directo de las minas de Sisapo. No en vano, el propio Augusto pudo haber accedido a este control una vez derrotado su oponente político, Antonio. Este hecho puede deducirse de la interpretación de Tovar $(1974,97)$ y G. Alföldy $(1987,54)$ del texto de la Segunda Filípica de Cicerón (Phil. 2, 19, 48), según la cuál Antonio habría participado en la societas sisaponensis en calidad de copropietario. Podríamos encontrar un nuevo indicador de este interés en la propuesta de algunos autores sobre una modificación de los límites interprovinciales que explicaría el desacuerdo entre Plinio (N.H., IV, 22) y Ptolomeo (II, 6, 58) que ubican Sisapo en la Bética y en la Tarraconense respectivamente. En opinión de Abascal y Espinosa (1989, 62 ), esta modificación, que otros investigadores sitúan en el tiempo que media entre las referencias de Plinio y Ptolomeo (Fernández Ochoa et alii, $1994,22)$, pudo hacerse efectiva en época augústea. Obviamente, se justificaría este reajuste en razón de la conveniencia de integrar el área minera de Sierra Morena a la Tarraconense, a fin de garantizar el control directo de la explotación por parte del Emperador.

A la prosperidad que debió suponer para el núcleo una coyuntura económica favorable, debe añadirse un hecho de no menos interés: el de su inserción en una de las vías destinadas a enlazar Emerita Augusta y Caesaraugusta. El viejo camino, soporte de influencias y transacciones de griegos, iberos y púnicos, se integra ahora en la sistematización de la red caminera romana: Per Lusitaniam ab Emerita Caesareagusta, injertando el núcleo sisaponense en una articulada malla que premió con la continuidad el acierto de su estratégica ubicación original (Zarzalejos, 1995, 160 ss). La actividad de esta vía encuentra reflejo en la llegada al centro de producciones de origen itálico que pudieron acceder por el segmento norte de la ruta que enlaza con el valle del Ebro; o bien, a través de las conexiones que, hacia el este, posibilitaban la comunicación con las zonas mineras de Cartagena. Ambas posibilidades no son excluyentes, sino complementarias, según autoriza a pensar la presencia de monedas de Cartagonova y de Caesaraugusta, testimonio del desplazamiento de personas y bienes por ambos caminos. Asimismo, el tránsito del tramo comprendido entre Sisapo y Mérida debió ser notablemente activo por estos tiempos, según hemos constatado a través de la distribución de materiales cerámicos y numismáticos en ambos núcleos y algunos enclaves intermedios establecidos en la vía. 
Las conexiones con la Bética se muestran igualmente fluidas, en especial con la capital provincial. En efecto, la vía directa de enlace entre Sisapo y Corduba debió convertirse en la principal arteria de canalización del mineral sisaponense. A través de este camino y del que enlazó Sisapo con Cástulo (Zarzalejos, 1995, 288 ss) pudieron acceder a La Bienvenida productos y bienes de origen bético.

\section{EL PERIODO JULIO-CLAUDIO}

El grado de prosperidad y afirmación que representa el momento anterior muestra clara continuidad en tiempos julio-claudios. La lectura arqueológica de los datos proporcionados por el sondeo A-1 (a b), trazado sobre una calle porticada de época augústea, nos ha permitido identificar las diferentes refacciones de su firme en este punto de la ciudad. Esta secuencia da muestra de la vitalidad económica de Sisapo en este período, al tiempo que registra de manera fiel la afluencia de productos de procedencia diversa.

\subsection{Indicadores materiales}

Los estratos pertenecientes a esta nueva etapa documentan la prosecución del comercio itálico durante el reinado de Tiberio y primeros años del de Claudio. Este hecho está acreditado por la presencia de t.s.i. datable en el primer tercio del siglo । d.C. Entre las formas con representación en nuestros repertorios se cuentan los platos Pucci X 5 (Conspectus 18.2, Goudineau 36 a) (Zarzalejos, 1995, fig.135, núm. 7 y fig.147, núm. 5), cuya datación de partida debe situarse a partir de la primera década del siglo I d.C.; o los platos Pucci X 9 (Conspectus 20.4, Goudineau $39 \mathrm{c}$ ) (Zarzalejos, 1995, fig.135, núm. 9), presente de manera notable en conjuntos datados a partir del primer tercio del siglo I d.C. (Conspectus, 1990, 86). También está testimoniada la llegada de las copas de forma Pucci XXIII (Conspectus 32.2, Goudineau 32 y 42) (Zarzalejos, 1995, fig.136, núm. 16) que experimentan su etapa de mayor auge a partir del 10 d.C. (Pucci, 1985, 391). El tipo evolucionado Goudineau 42 se localiza en Magdalensberg en contextos del segundo cuarto del siglo I d.C., dato corroborado por yacimientos hispanos con registros de época tiberio-claudia (Pérez González, 1989, 186).

La progresiva sustitución de los productos itálicos por las series vasculares fabricadas en la Galia tuvo lugar a partir de época de Claudio. Así, 
se observa claramente a través de la presencia de perfiles de forma Drag.18, Drag.15/17 y Drag.24/25 con rasgos de cronología temprana (Fernández Ochoa et alii, 1994, fig.26, núm. 19; fig.27, núm. 20-22; fig.35,núm. 11 y 13). También se han documentado vasos Ritt.9 realizados con técnica de marmorata, circunstancia que permite su adscripción al período comprendido entre el 40 y 70 d.C. (Fernández Ochoa et alii, 1994, fig.16, núm. 19 y 20). Al margen de la información temporal deducible de tan singular producción, su vínculo con un centro alfarero concreto, permite aportar datos sobre su origen, hecho que se certifica con la lectura de las marcas de officina halladas en el yacimiento. Todas ellas corresponden a alfareros de La Graufesenque como Lucceivs, Vitalis o Felix (Fernández Ochoa y Zarzalejos, 1991, 276-7).

Asimismo, en estos momentos el mercado sisaponense da muestra de su inmediata incorporación a los circuitos de difusión de las producciones tempranas de T.S.H fabricada en Andújar. Se han constatado perfiles con resabios gálicos de la forma Hisp.15/17 (Fernández Ochoa et alii, 1994, fig.2, núm. 17; fig.10, núm. 6; fig.17, núm. 29), datados en Andújar en época claudia, o incluso pre-claudia (Roca, 1976, 36). También queremos destacar la posible presencia de un fragmento adjudicable a las formas decoradas hemisféricas de las producciones tempranas del taller bético (Fernández Ochoa et alii, 1994, fig.27, núm. 30), cuya fabricación arrancaría de época tiberiana, registrando especial florecimiento en tiempos claudios (Fernández García, 1987, 485).

En cuanto a las cerámicas de paredes finas, la época julio claudia supone la desaparición de las series de origen extrapeninsular, que serán sustituidas, en un primer momento, por producciones de procedencia bética. Hemos testimoniado las formas Mayet XXXIV (Fernández Ochoa et alii, 1994, fig.20, núm. 57), cuyo lugar de fabricación se encuentra en algún punto del curso medio o bajo del Guadalquivir (López Mullor, 1989, 163); Mayet XXXVII (Fernández Ochoa et alii, 1994, fig.12, núm. 22; fig.27, núm. 34) y Mayet XXXVIII (Fernández Ochoa et alii, 1994, fig.20, núm. 51).

Desde mediados del siglo । d.C. el registro arqueológico de Sisapo refleja la afluencia de producciones habitualmente adscritas al entorno de Emérita, tales como la forma Mayet XLIII (Fernández Ochoa et alii, 1994, fig.20, núm. 52-55).

Por su parte, el conjunto de numerario asociado a estratos de cronología julio-claudia está constituido por un semis de Tiberio de Cartagonova (RPC 175), un as de Tiberio de Cascantum (RPC 425), un as de Tiberio de Celsa (RPC 279), cuatro ases de Tiberio de Emérita (RPC 22, 41 y 42), un as de Tiberio de Itálica (RPC 65), un denario de Tiberio de 
Lugdunum ( $\mathrm{RIC} I, 2)$, un as de Calígula de Roma (RIC I,35), un cuadrante de Claudio de Roma (RIC I,90), un sestercio de Claudio de Roma (RIC I,93) y tres ases de Claudio de imitación local (RIC I,66) (Arévalo, 1995, 135).

\subsection{La ciudad en tiempos julio-claudios: actividades económicas $y$ comerciales}

Los indicadores materiales que acabamos de enunciar permiten comprobar el dinamismo del centro durante este período, al tiempo que se hacen eco de fenómenos económicos con repercusión en todo el ámbito peninsular. Así, hemos dado cuenta de la sustitución de las producciones de T.S.I. por las de procedencia gálica, en momentos remontables a época de Tiberio y con toda claridad desde tiempos claudios. Proceso semejante se registra en yacimientos próximos al que nos ocupa, como Mirobriga (Pastor et alii, 1992, 80) y Oretum (Nieto et alii, 1980, fig.54, núm. 261264), entre otros. La llegada a La Bienvenida de estos materiales debió hacerse efectiva a través del segmento viario que comunica la ciudad con el valle del Ebro. Esta hipótesis podría encontrar reflejo en el hallazgo de numerario procedente de este área, como testimonio del movimiento de población. Las relaciones comerciales con la Bética están asimismo bien documentadas, existiendo estrechos lazos con zonas de la Alta Andalucía y del curso medio del Guadalquivir. Este hecho está avalado por la presencia de materiales tempranos de Andújar (TSH y lucernas), cerámicas romanas de imitación con barniz rojo, así como por el registro nada desdeñable de cerámicas de paredes finas fabricadas en talleres meridionales, amén del ejemplar monetal de Itálica. Lógicamente el soporte físico de estas transacciones debieron ser los caminos que unían Sisapo con Cástulo y Córduba.

Por su parte, el tramo viario que conducía a Mérida parece ser objeto de importante tránsito desde mediados del siglo । d.C. Disponemos, en este sentido, de la información proporcionada por las cerámicas de paredes finas fabricadas en la capital lusitana. Su documentación conjunta con las series béticas muestran el carácter de centro dinámico que desempeñó Sisapo. La constatación de los productos emeritenses resulta muy significativa puesto que su dispersión parece restringirse a la provincia lusitana y algunos puntos, no muchos, del extremo occidental de la Bética (Mayet, 1975, 146, mapa 7). Su registro en Medellín (Del Amo, 1973,61), punto que se ha dado en considerar inicio en el cómputo de millas para la descripción de la vía 29 del Itin. Ant., y Miróbriga (Pastor et alii, 1992, 83) subraya nuestra afirmación. No obstante, el abundante numerario emeri- 
tense perteneciente a época tiberiana advierte de la enorme fluidez de movimientos desde la segunda década del siglo । d.C.

La conjugación de todos los datos que obran en nuestro poder, permitirían defender, en esencia, la inserción de Sisapo en amplios circuitos de circulación de bienes de procedencia diversa. El hecho permite apreciar el desahogado nivel de vida de sus moradores y, como no, alumbra la continuidad de la explotación minera en una etapa para la cuál no existen alusiones directas sobre el particular en las fuentes antiguas. Por otra parte, cabría preguntarse acerca del sistema de gestión de que fueron objeto las minas de Sisapo en tiempos julio-claudios. Opinamos que pudo mantenerse el funcionamiento de la societas sisaponense, pese a la ausencia de referencias documentales. Según $\mathrm{C}$. Domergue, en la primera mitad del siglo । d.C. pudo proseguir la explotación en régimen de arrendamiento por publicani en algunas comarcas mineras de la Bética, entre ellas Sisapo y algunas minas del área cordobesa recuperadas por el Estado tras la política de confiscaciones realizada por Tiberio (Domergue, 1990, 270-1). Este último aspecto podría encontrar reflejo en la abrumadora presencia de monedas de esta época constatada en la ciudad.

\section{LA ETAPA FLAVIA}

El nuevo período no evidencia ruptura alguna con la situación precedente. No obstante, la interesante información que proporcionan algunos conjuntos materiales asociados a estratos del último tercio del siglo I d.C. aconseja abordar un comentario específico sobre esta etapa.

\subsection{Indicadores materiales}

En el marco de la TS debemos anotar el mantenimiento de las importaciones de origen sudgálico, si bien se aprecia con claridad su receso ante la imposición de los productos de talleres hispánicos. Están testimoniadas formas lisas, como los platos Drag.15/17, con pared de tendencia exvasada (Fernández Ochoa et alii, 1994, fig.1, núm. 6 y 7) y las formas Drag.35 o 36 (Fernández Ochoa et alii, 1994, fig.16, núm. 21) con decoración de hojas de agua a la barbotina; esta modalidad decorativa se encuadra entre los años 60 y 120 d.C. en La Graufesenque, si bien hacia el 90-100 comienza a rarificarse en gran medida.

La TSH constituye el conjunto cerámico más nutrido, mostrando un predominio cuantitativo de los materiales originarios de Andújar, aunque en 
convivencia con series procedentes del Valle del Ebro. Entre los perfiles más característicos de esta etapa se encuentran vasos de forma 24/25 con decoración burilada (Fernández Ochoa et alii, 1994, fig.11, núm. 13; fig.27, núm. 28) y los de forma 35 (Fernández Ochoa et alii, 1994, fig.11, núm. 12; fig.18,núm. 31). También se han recuperado fragmentos asignables a la forma 33 (Fernández Ochoa et alii, 1994, fig.10, núm. 7; fig.17, núm. 30 ) cuyas fechas de fabricación se centran entre la segunda mitad del siglo I y comienzos de la centuria siguiente (Mayet, 1984, I, 73).

Los materiales sin contexto avalan la presencia mayoritaria de los productos de Andújar; tenemos registrados sellos con las marcas EX.OF. G.I.C., EX OF CA, EX.OF. P.T., EX O TIF y EX OF C.L., todos ellos bien constatados en el citado centro bético y sus áreas de comercio (Fernández Ochoa y Zarzalejos, 1993, 200). Destacamos, además, la presencia de lucernas fabricadas en Andújar, con marcas y rasgos propios del taller bético (Fernández Ochoa et alii, fig.15, núm. 4-6). También acreditan su pervivencia en estas fechas avanzadas del siglo I d.C., las cerámicas romanas de imitación con barniz rojo (Fernández Ochoa et alii, 1994, fig.4, núm. 30; fig. 19, núm. 47).

Asimismo, nos parece interesante la documentación de cerámicas de paredes finas de origen emeritense (forma Mayet XLIII) (Fernández Ochoa et alii, 1994, fig.20, núm. 52-55), en convivencia con series de origen bético (Fernández Ochoa et alii, 1994, fig.20, núm. 51).

En cuanto al testimonio numismático se refiere, tan sólo contamos con un as de Vespasiano de ceca ilegible (Arévalo, 1995, 135).

\subsection{La ciudad en época flavia: actividades económicas y comerciales}

Desde los tiempos flavios se asiste ya al desplazamiento definitivo de los productos cerámicos de origen extrapeninsular. Las series de procedencia hispánica se imponen de modo masivo, permitiendo registrar fenómenos muy interesantes en el análisis de la repartición de las esferas comerciales de los centros productores de TSH (Fernández Ochoa y Zarzalejos, 1988-89, 469). La documentación conjunta en Sisapo de productos de los talleres del Valle del Ebro y de la Bética (Andújar) está testimoniada desde etapas anteriores, según hemos comentado más arriba. La afluencia de materiales del valle del Ebro hacia Sisapo pudo producirse, lógicamente, a través del segmento de la vía 29 que la comunicaba directamente con Caesaraugusta. Así lo acreditaría la nómina de hallazgos existente en el área afectada por el paso de esta ruta (Garabito et alii, 
$1988,131-140)$. Ahora bien, no habría que descartar en modo alguno que tales productos arribaran a La Bienvenida desde la propia capital lusitana, dado el rol de redistribución de materiales tricienses que Emérita posee sin duda alguna (Mayet, 1984, I, 219). A este respecto, es muy interesante el seguimiento que hace Blázquez Cerrato (1992, 268 ss.) de este fenómeno a través de la dispersión de acuñaciones emeritenses en el Conventus Caesaraugustanus.

Por otra parte, esta importante penetración meridional de los potentes centros del valle del Ebro, no halla correspondencia en una hipotética ampliación del área de mercado de la TS fabricada en Andújar. Existen en la bibliografía breves referencias sobre la identificación de TSH del taller jiennense en Coca (Segovia) (Blanco, 1987, 27; Idem, 1988, 55), aunque debemos advertir que, según los datos publicados, se trata de identificaciones carentes del oportuno contraste arqueométrico que certifique este origen. En el estado actual de la cuestión, por tanto, no ha podido ser plenamente confirmada la catalogación de TSH de origen bético en importantes centros de consumo que superan hacia el $\mathrm{N}$. la línea imaginaria que traza el Guadiana. Este hecho llama la atención si se considera que otros productos fabricados en Andújar, como las lucernas, están presentes, aunque de modo esporádico, en yacimientos norteños (Morillo, 1992, fig.11, núm. 14). En relación con el problema de la distribución de estos objetos han visto la luz nuevas aportaciones que ponen de manifiesto la realización de lucernas de «tipo Andújar», en otros centros de la Bética, como la propia Corduba (Bernal, 1993, 207-220), y en la Lusitania (Mérida) (García Giménez, et alii, e.p.). Aún cuando parece un hecho que tales producciones no son originarias en modo exclusivo de Andújar, no es menos cierto que la analítica aplicada a fragmentos del área NW de la Península, permite atisbar una mínima presencia de estos alfares jiennenses en la zona citada.

En su día nos planteamos que la disparidad en la difusión de productos salidos de un mismo taller pudiera obedecer a causas relacionadas con la propia gestión del centro emisor. Esto es, lucernas y vasos de TSH pudieron ser objeto de distinto negotiator y seguir cauces independientes de comercialización. Sin embargo, otra explicación más racional podría manejarse en este sentido, cual es la ausencia de una producción altoimperial masiva de lucernas por parte de los alfares del Valle del Ebro. Este hecho podría explicarse en razón de la íntima conexión entre las lucernas y la materia prima que surtía la combustión en la lámpara: el aceite. En otras palabras, a través de estudios muy recientes comienza a certificarse que las lucernas meridionales halladas en centros de consumo norteños se encuentran en íntima relación con el comercio de aceite bético hacia el $\mathrm{N}$. 
hispano. Este fenómeno está siendo abordado de manera exhaustiva por A. Morillo en su tesis doctoral sobre la lucernaria romana del NW peninsular.

Según los datos expuestos, es evidente que la ciudad mantiene su bienestar en las postrimerías del siglo I d.C. El marco económico que garantiza el mantenimiento de este modo de vida próspero, indudablemente se halla en relación estrecha con la continuidad de las explotaciones mineras. Además de las apuradas descripciones de Plinio sobre los usos y los sistemas de obtención del minio (N.H. XXXIII, 32, 36, 38, 40 y 99-100), no parece inverosímil relacionar con las minas de Sisapo algunos lingotes de origen bético con las marcas IMP.CAES. y VESP.AVG., dado que son las únicas minas que continúan en esta época perteneciendo al Estado y gestionadas por una sociedad de publicanos (Domergue, 1990, 287).

\section{EPILOGO. LA CIUDAD DE SISAPO ENTRE LOS SIGLOS ॥ $Y I D D . C$.}

Los cortes estratigráficos que hemos manejado para realizar esta aproximación histórica muestran clara continuidad en la ocupación durante la primera mitad del siglo ॥ d.C. Las evidencias materiales, bien ejemplificadas por las producciones de TSH (Fernández Ochoa et alii, 1994, fig.11; fig.12, núm. 18-21), permiten trazar un panorama coincidente con el que acabamos de sintetizar para la época flavia, si bien, se aprecia una mayor representación de cerámicas de procedencia bética. El escaso material numismático de este momento - un as de Adriano de la ceca de Roma (RIC I,832) y un sestercio de Antonino Pío de la ceca de Roma inclasificableno permite entrar en una profunda valoración; pero no desdice la evidencia material. Una vez más, debemos anotar que la actividad minera pudo ser el telón de fondo del mantenimiento del nivel de vida en la ciudad. La posible atribución a Sisapo de la marca NER. AVG. hallada sobre lingotes béticos, defendida por Domergue $(1990,287)$ reafirma nuestra hipótesis.

No podemos precisar aún el momento exacto, pero hacia la mitad o el último tercio del siglo ॥ d.C., cesa la información estratigráfica en los cortes analizados, circunstancia a la que se suma la práctica ausencia de testimonios monetales. No son muchos los datos de que disponemos para la evaluación de las últimas fases de actividad del yacimiento. Carecemos, por el momento, de manifestaciones materiales adscritas con claridad al siglo III d.C., salvo alguna lucerna (Fernández Ochoa y Seldas, 1987, 266 ss.) y tan sólo un sestercio de Alejandro Severo (RIC IV.II, 456). Ello abogaría por una importante transformación del núcleo por estas fechas, pero no permite abonar en absoluto, la hipótesis de un abandono completo. En 
principio, podría atribuirse a un momento tardío una serie de estructuras domésticas de repercusión puntual en el área central del yacimiento, cuyos muros amortizan materiales constructivos de la época anterior. Su adjudicación a fechas bajas puede mantenerse en virtud de hallazgos de numerario perteneciente a emperadores del siglo IV a.C. (Graciano, Máximo, Valentiniano, Teodosio, Arcadio y Honorio). Asimismo, el yacimiento ha proporcionado otras evidencias materiales que permiten inferir que pudo ser objeto de ocupaciones durante el Bajo Imperio (Aurrecoechea et alii, 1986, 276-77). En las campañas más recientes (1997-1999), los trabajos desarrollados en la domus de las columnas rojas han atestiguado la existencia de niveles tardíos asentados sobre las estructuras ya arruinadas de la casa. El tipo de ocupación difiere sensiblemente de la vigente en el período altoimperial, caracterizándose, según los datos disponibles en este momento, por la proliferación de estructuras de tipo «basurero» y la existencia de algunos restos relacionables con la manipulación in situ de mineral de plomo. Por otra parte, debe tenerse en cuenta que en tiempos de San Agustín la producción de cinabrio debía mantenerse activa puesto que en una de sus epístolas informa de su exportación a Cartago y a Egipto (Epist. 30).

Con posterioridad a estos momentos la ciudad se abandonó con carácter definitivo y nunca más volvió a recuperar la prosperidad y riqueza de que dio muestras durante más de siete siglos. La causa segura de su ruina debió ser el abandono de las minas en que había cifrado su modo de vida desde el origen. La crisis afecta a buena parte de las explotaciones de Sierra Morena a partir de fines del siglo II d.C., si bien algunas experimentan cierta recuperación que les mantiene activas hasta el fin del siglo IV (El Centenillo) (Domergue, 1990, 215).

\section{BIBLIOGRAFIA CITADA EN EL TEXTO}

ABASCAL, J. M. y ESPINOSA, U. (1989): La ciudad hispano-romana. Privilegio y poder, Logroño. ALFöLdY, G. (1987): Römisches Städfewosen auf der Neukastilischen Hochebene, Heidelberg. ArÉvalo González, A. (1993): Las monedas de Obulco, Tesis doctoral microfilmada, Universidad Autónoma de Madrid.

Arévalo Gonzalez, A. (1995): «Sobre la circulación monetaria de la ciudad de Sisapo (Almodóvar del Campo, Ciudad Real», Actas I Encuentro Peninsular de Numismática Antigua. La moneda hispánica. Ciudad y Territorio, Anejos de AEspA XIV.

ArÉvalo, A. y ZaRZALEJOS, M. (1996): «Apuntes para las claves interpretativas de la Sisapo republicana", XXIII C.N.A., Elche 1995.

aurrecoechea, J., Fernández, Ochoa, C. y Caballero, A. (1986): "Mobiliario metálico romano del yacimiento romano de La Bienvenida, Ciudad Real», Oretum, II, Ciudad Real.

BallL, A. (1976): «Notas de Arqueología Palentina", Institución Tello Téllez de Meneses, núm. 37 , Palencia.

Beltrán, M. (1990): Guía de la Cerámica Romana, Zaragoza.

BEndALA, M. (1990): «El plan urbanístico de Augusto en Hispania: precedentes y pautas macroterritoriales», Stadtbild und Ideologie. Die Monumentalisierung hispanischer Städte zwischen Republik und Kaiserzeit, Madrid 1987, München. 
BernaL, D. (1993): «Una pieza excepcional del Museo Nazionale de Roma y el problema de las lucernas tipo Andújar», Espacio, Tiempo y Forma, Serie II, Historia Antigua 6.

BLANCO, F. (1987): Moneda y circulación monetaria en Coca. Siglo II a.C. al v d.C., Segovia.

BLANCO, F. (1988): "Coca arqueológica», Revista de Arqueología, 81.

Blázouez Cerrato, C. (1992): La dispersión de las monedas de Augusta Emerita, Cuadernos Emeritenses, 5, Mérida.

BlÁzQuez CerRato, C. (1993): "Coin circulation in Extremadura during the Republican and High-Imperial Periods", XI CIN, Lovain-La-Neuve.

CONSPECTUS (1990): AA.VV. Conspectus formarum terrae sigillatae italico modo confectae, Bonn.

Chaves TRISTÁN, F. (1987-88): «Aspectos de la circulación monetaria de dos cuencas andaluzas: Riotinto y Castulo (Sierra Morena)», Habis, 19, Sevilla.

CHIC, G. (1991): “Estrabón y la práctica de la amalgama en el marco de la minería sudhispánica: un texto mal interpretado», La Bética en su problemática histórica (Ed. C. González Román), Granada.

DeL AMo, M. (1973): «Estudio preliminar sobre la romanización en el término de Medellín (Badajoz)», NAH, 2, Madirid.

Delgado, M. et alli (1975): Fouilles de Conimbriga IV. Les Sigillées, París.

Domergue, C. (1967): «La mine antique de Diógenes (Province de Ciudad Real)», Melanges de la Casa de Velázquez, 3.

Domergue, C. (1990): Les mines de la Péninsule lbérique dans l'Antiquité Romaine, Collection de L'École Française de Rome, 127, Roma.

Fernández, J., Granados, J. y GonzÁlez, R. (1992): Marcas de Terra Sigillata del Museo Arqueológico de Ibiza, Ibiza.

FERnÁndez García, M.I. (1987): “Las primeras generaciones de alfareros del centro de producción de los Villares de Andújar (Jaén)", Jornades Internacionals d'Arqueología Romana, Granollers.

Fernández OchoA, C. y Seldas, I. (1987): «Lucernas romanas de La Bienvenida», Oretum, III, Ciudad Real.

FERNÁNDEZ OCHOA, C y ZARZALEJOS, M. (1991): "Las producciones de terra sigillata altoimperial de Sisapo (La Bienvenida, Ciudad Real. I. Terra sigillata itálica y gálica», Espacio, Tiempo y Forma, Serie II, Historia Antigua, T.4.

FERNÁNDEZ OCHOA, C y ZARZALEJOS, M. (1993): «Las producciones de terra sigillata aitoimperial de Sisapo (La Bienvenida, Ciudad Real. II. Terra sigillata hispánica», Espacio, Tiempo y Forma, Serie II, Historia Antigua, T.6.

Fernandez Ochoa, C y Zarzalejos, M., Hevia, P. y Esteban, G. (1994): Sisapo I. Excavaciones arqueológicas en La Bienvenida, Almodóvar del Campo (Ciudad Real), Patrimonio HistóricoArqueología Castilla-La Mancha, 10, Toledo.

Fernández Ochoa, C y Zarzalejos, M., Esteban, G. y Hevia, P. (1995): “Las raíces de Sisapo», XIV Congreso Internacional de Arqueología Clásica, Tarragona, 1993.

Garabito, T., Pradales, D. y Solovera, E. (1988): "Los alfares romanos riojanos y la comercialización de sus productos en la región de Castilla-La Mancha», I Congreso de Historia de Castilla-La Mancha, T.IV.

García BELLIDO, M.P. (1982): Las monedas de Castulo con escritura indígena, Barcelona.

GaRcía BeLlido, M.P. (1986): «Nuevos documentos sobre minería y agricultura romanas en Hispania", AEspA., 59, Madrid.

GARCIA Y BELLIDO, A. (1970): Los hallazgos cerámicos del área del Templo romano de Córdoba, AEspA. Anejos, V, Madrid.

Garcia R., Bernal, D. y Morillo, A. (e.p.): «Consideraciones sobre los centros productores de lucernas tipo Andújar: Análisis arqueométrico de materiales procedentes de Los Villares de Andújar (Jaén) y de la Submeseta Norte", I Congreso Nacional de Arqueometría, Granada.

López Mullor, L. A. (1989): Las cerámicas romanas de paredes finas en Cataluña, 2 vol. Quaderns Científics i Tècnics, Barcelona.

MAYET, F. (1975): Les céramiques a Parois Fines dans la Péninsule Iberique, París.

MAYET, F. (1984): Les céramiques sigillées hispaniques, 2 vol. París.

MELCHOR GIL E. (1993): «Vias romanas y explotación de los recursos mineros de la zona norte del Conventus Cordubensis", Anales de Arqueología Cordobesa, 4.

MONTESINOS, J. (1991): Terra Sigillata en Saguntum y Tierras Valencianas, Sagunto. 
Morillo, A. (1992): Cerámica romana de Herrera de Pisuerga (Palencia-España). Las Lucernas, Santiago de Chile.

Nieto, G., Meseguer, J. y Poyato, C. (1980): Oreto I, EAE, 114, Madrid.

OTERO MORÁN, P. (1993): "Consideraciones sobre la presencia de acuñaciones celtibéricas en zonas mineras de la Hispania Ulterior", XI CIN, Lovain-La-Neuve.

OXE, A. y COMFORT, H. (1968): Corpus Vasorum Arretinorum, Bonn.

Pastor, M., Pachón, J. A. y Carrasco, J. (1992): Mirobriga. Excavaciones en el "Cerro Cabezo" (Capilla, Badajoz). Campañas 1987-1988, Mérida.

Pérez Almoguera, A. (1983-4): "Las marcas de Terra Sigillata de llerda», Pyrenae, 19-20, Barcelona.

Pérez González, C. (1989): Cerámica romana de Herrera de Pisuerga (Palencia-España). La Terra Sigillata, Santiago de Chile.

Pérez Outeriño, B. (1990): Sellos de alfareros en Terra Sigillata Itálica encontrados en Mérida, Cuadernos Emeritenses, 3, Mérida.

Puccl, G. (1985): «Terra Sigillata Italica», Atlante delle Forme Ceramiche II, Roma.

RocA, M. (1976): Sigillata Hispánica producida en Andújar (Jaén), Instituto de Estudios Giennenses, Jaén.

Romero, M.V. (1985): Numancia I. La Terra Sigillata, EAE, 146, Madrid.

SÁNCHEZ-LAFUENTE, J. (1990): Terra Sigillata de Segobriga y ciudades del entorno: Valeria, Complutum y Ercávica, Madrid.

Tovar, A. (1974): Iberische Landeskunde, Baetica. Baden-Baden.

VentuRA, A. (1993): "Susum ad montes S(ocietatis) S(isaponensis): nueva inscripción tardorrepublicana de Córduba", Anales de Arqueología Cordobesa, 4.

ZARZALEJOS, M. (1994): «La búsqueda de Sisapo: hipótesis sobre la reducción geográfica de la capital del cinabrio hispano", Espacio, Tiempo y Forma, Serie II, Historia Antigua, T.7.

ZARZALEJOS, M. (1995): Arqueología de la región sisaponense. Aproximación a la evolución histórica del área SW. de la provincia de Ciudad Real, Tesis Doctoral microfilmada, 1994, Universidad Autónoma de Madrid.

Zarzalejos, M., Fernández Ochoa, C., Hevia, P. y Esteban, G. (1994): «Excavaciones en La Bienvenida (Ciudad Real). Hacia una definición preliminar del horizonte histórico arqueológico de la Sisapo antiglia”, Arqueología de Ciudad Real en la U.A.M., Patrimonio HistóricoArqueología Castilla-La Mancha, 6, Toledo.

Zarzalejos, M., Fernández Ochoa, C., Hevia, P. y Esteban, G. (1995): “Cerámicas griegas de Sisapo (La Bienvenida, Ciudad Real)", XXII CNA, Vigo.

ZARZALEJOS, M. (e.p.): «El yacimiento arqueológico de La Bienvenida (Almodóvar del Campo). Evolución metodológica en proyectos de investigación a largo plazo". El Patrimonio Arqueológico en Ciudad Real al final del milenio. Métodos de trabajo y últimas actuaciones, Valdepeñas, 1999. 


\section{Cuadro 1}

Resumen de especies cerámicas significativas y material numismático

\begin{tabular}{|c|c|c|}
\hline Período cronológico & Materiales cerámicos & Monedas \\
\hline TARDORREPUBLICANO & $\begin{array}{l}\text { - Campaniense B y B-oïde (Morel } \\
\text { 2254, 2255a y d, 2286c, 1413f, } \\
\text { 1415 b1, 2323c) } \\
\text { - Paredes finas (Mayet II y III) } \\
\text { - Anforas (Dressel 1 B o C) } \\
\text { - Lucernas (Dressel 3) }\end{array}$ & $\begin{array}{l}\text { - kastilo (García-Bellido IV y Vla) } \\
\text { - Obulco (Arévalo III, IV y Va) } \\
\text { - Corduba (Vives CXVIII-1) } \\
\text { - belikio (Vives XLIV-3) } \\
\text { - sekaisa (Vives LXV-11) }\end{array}$ \\
\hline AUGÚSTEO & $\begin{array}{l}\text { - TSI (Consp. 11.1, 12.2, 12.3, } \\
\text { 14.1, 23.2. Ateius, Archebus, } \\
\text { Naevius) } \\
\text { - Paredes finas (Mayet V B, VIII B, } \\
\text { VIII C, XIII, XIV A, XXI) } \\
\text { - Cerámica romana de imitación } \\
\text { con barniz rojo (Martínez lb, ic, Ilc) }\end{array}$ & $\begin{array}{l}\text { - Caesaraugusta (RPC } 322 \text { y 314) } \\
\text { - Carthago Nova (RPC 170) } \\
\text { - Ercavica (RPC 459) } \\
\text { - Colonia Patricia (RPC 129) } \\
\text { - lulia Traducta (RPC 108) } \\
\text { - Nemausus (RPC 523) }\end{array}$ \\
\hline JULIO-CLAUDIO & $\begin{array}{l}\text { - TSI (Consp.18.2, 20.4, 23.2, 32.2) } \\
\text { - TSG (Graufesenque. Drag.15/17, } \\
\text { 18, 24/25, Ritt.9, Drag.29. } \\
\text { Marmorata) } \\
\text { - TSH (Andújar. Hisp.15/17, formas } \\
\text { decoradas hemisféricas, 29) } \\
\text { - Paredes finas (Mayet XXXIV, } \\
\text { XXXVII A, XXXVIII, XLIII) } \\
\text { - Lucernas (Dressel 11, 12, der. } \\
\text { Dressel 3) } \\
\text { - Cerámica romana de imitación } \\
\text { con barniz rojo (Martínez lb, Ic, } \\
\text { lib, Ilc) }\end{array}$ & $\begin{array}{l}\text { - Carthago Nova de Tiberio (RPC } \\
\text { 175) } \\
\text { - Cascantum de Tiberio (RPC 425) } \\
\text { - Celsa de Tiberio (RPC 279) } \\
\text { - Emerita de Tiberio (RPC 22, } 41 \text { y } \\
\text { 42) } \\
\text { - Italica de Tiberio (RPC 65) } \\
\text { - Lugdunum de Tiberio (RIC I, 2) } \\
\text { - Roma de Calígula (RIC I, 35) } \\
\text { - Roma de Claudio (RIC I, 90 y 93) } \\
\text { - Imitación local de Claudio (RIC I, } \\
\text { 66) }\end{array}$ \\
\hline FLAVIO & $\begin{array}{l}\text { - TSG (Drag.15/17, 35, 36, 37?) } \\
\text { - TSH (Andújar y Valle del Ebro. } \\
\text { Hisp.24/25, 35, 33, 29, 37) } \\
\text { - Paredes finas (Mayet XXXV|I B, } \\
\text { XLII, XLIII) } \\
\text { - Lucernas (Der. Dressel 3) } \\
\text { - Cerámica romana de imitación } \\
\text { con barniz rojo }\end{array}$ & - Vespasiano \\
\hline ss. II-IV d.C. & $\begin{array}{l}\text { - TSH (Andújar y Valle del Ebro. } \\
\text { Hisp. 7, 15/17, 24/25, 27, 44, 37) } \\
\text { - TSHB (F.9) }\end{array}$ & $\begin{array}{l}\text { - Adriano } \\
\text { - Antonino Pío } \\
\text { - Alejandro Severo } \\
\text { - Máximo } \\
\text { - Valentiniano } \\
\text { - Graciano } \\
\text { - Teodosio } \\
\text { - Honorio } \\
\text { - Arcadio }\end{array}$ \\
\hline
\end{tabular}

